\title{
Investigation bending behaviors of the slabs with glass fiber reinforced polymer composite and steel bars
}

\author{
Alper Karadis $^{1}$ (D), Kabil Cetin ${ }^{2}$ (D), Taha Yasin Altıok ${ }^{1}$ (D), Ali Demir" (iD \\ ${ }^{1}$ Manisa Celal Bayar University, Department of Civil Engineering, Manisa, Turkey \\ ${ }^{2}$ Manisa Celal Bayar University, Kula Vocational School, Manisa, Turkey
}

\begin{abstract}
Glass fiber reinforced polymer (GFRP) composites have been frequently used in engineering applications in recent years. GFRP composites produced by using glass fiber and epoxy resin have significant advantages such as high strength, lightness, and resistance against corrosion. However, GFRP composites exhibit a more brittle behavior than steel bars. This study aims to investigate both the experimental and numerical bending behavior of slabs with GFRP bars, steel bars, and polypropylene fiber. Within the scope of experimental studies, 5 slabs were built. Two slabs called SS- 1 and SS-2 have only steel bars. Two slabs called GFRPS- 1 and GFRPS-2 have only GFRP composite bars. A slab called GFRPS-F has both GFRP composite bars and polypropylene fibers. Polypropylene fibers are added to fresh concrete to improve the slab's ductility. Threepoint bending tests have been carried out on the slabs. All slabs are subjected to monotonic increasing distributed loading until collapse. As a result of tests, GFRPS slabs have carried \%53 higher load than SS slabs. However, the SS slabs have exhibited a more ductile behavior compared to the GFRPS slabs. GFRPS slabs have more and larger crack width than other slabs. The addition of 5\% polypropylene fiber by volume to concrete has a significant contributed to ductility and tensile behavior of slab. The average displacement value of GFRPS-F slab is $22.3 \%$ larger than GFRPS slab. GFRPS-F slab has better energy consumption capacity than other slabs. The energy consumption capacity of GFRPS-F slab is 1.34 and 1.38 times that of SS and GFRPS slabs, respectively. The number of cracks in GFRPS-F slab is fewer than GFRPS slabs. The fibers have contributed to the serviceability of the GFRPS slabs by limiting the displacement and the crack width. GFRPS-F exhibits elastoplastic behavior and almost returns to its first position when the loading is stopped. In addition, experimental results are verified with numerical results obtained by using Abaqus software. Finally, it is concluded that GFRP composite bars can be safely used in field concretes, concrete roads, prefabricated panel walls, and slabs.
\end{abstract}

\section{Keywords}

Composite bar; GFRP; Polypropylene fiber; Slab; Finite element analysis

Received: 22 September 2021; Accepted: 12 December 2021

ISSN: 2630-5763 (online) (C 2021 Golden Light Publishing All rights reserved.

\section{Introduction}

Composite bars have been commonly used in civil engineering applications in recent years. GFRP bars have high corrosion resistance. This property provides a great advantage to composite reinforcements. When the reinforced concrete (RC) structures are investigated, it has been observed that one of the main causes of damage is corrosion [1]. The corrosion greatly reduces the durability of the

\footnotetext{
Corresponding author

Email: ali.demir@cbu.edu.tr
} 
structures. Therefore, the use of composite bars in $\mathrm{RC}$ members has emerged as a good alternative against corrosion [2]. GFRP bars have the advantages such as high tensile strength, lightweight and high corrosion resistance compared to steel bars. Therefore, it could be used in port structures, subway lines, field concretes, and concretes using mesh reinforcement due to its high service life. It is commonly used in the construction industry, especially in Europe, the United States, and Russia. Due to the ease of application of GFRP bars, they are more economical than steel bars. Price of GFRP bar per one meter is $20 \%$ more expensive than steel bar. The GFRP composite bars used in this study are approximately 10 times lighter. These bars have no corrosion problem. Therefore, transportation, labor and maintenance costs are cheaper in GFRP bars [3]. In addition, Wang et al. [4] investigated the behavior of FRP composite reinforcements under the influence of temperature, and determined that they retained a very high level $(90 \%)$ of their original rigidity under a temperature of about $350^{\circ} \mathrm{C}$.

The use of GFRP bars on the behavior of structural members in RC structures has attracted the interest of researchers. Many scientific studies have been performed in which GFRP bars are used alone or together with steel bars in the structural members $[5,6]$. However, it has been observed that the researchers have mostly focused on the beam member. Qin et al. [3] investigated the effect of hybrid reinforcement ratio on the bending behavior of concrete beams using 3D FE models. Şahin [7] investigated the effect of the combination of GFRP and steel bars on the bending behavior and crack development of the beam members. The steel bars continued to carry the load, although the load dropped due to the rupture of GFRP bars under the loading. In addition, it was determined that the steel bars placed close to the tensile surface reduced the crack width. Unsal et al. [8] investigated the loaddisplacement relation, crack distribution and failure mode of the beams used together with GFRP and steel bars under static loading. It was concluded that the beams reinforced with GFRP and reinforced together with GFRP and steel bars have different deformation capacities. Large deformation was observed in beams where the reinforcement ratio was small. The beams with steel bars exhibited a stiffer behavior than the others. Maranan et al. [9] determined that the combination of GFRP, and steel reinforcements provides an increase in ductility, moment capacity, and energy consumption capacity. Abdalla [10] developed some approaches for the estimation of deflection of structural members reinforced with FRP subjected to bending moments. It has been determined that the results obtained by using these approaches are compatible with experimental results. Elamary and AbdElwahab [11] conducted an analytical study by using the FE model to simulate the behavior of the beams reinforced with GFRP and/or steel bars. In beams with used GFRP bars, larger cracks and higher displacements were seen compared to steel bars [7]. This situation is an important problem for the structures. In the literature, the use of GFRP bars in beams has been frequently investigated. Therefore, the number of studies in which it is used in slab is quite limited. Slabs mainly carry vertical loads and transmit them to beams, columns and shear walls. In addition, the distribution of earthquake loads to the vertical bearing elements is done by the slabs. In general, slabs are considered rigid in their plane. In this case, the distribution of the horizontal load to the vertical elements depends entirely on the rigidity of the slabs. Sham and Burgoyne [12] performed 12 internal load tests to determine the effect of steel fiber volume content on the initial crack and ultimate load capacity of simply supported concrete slabs. Beckett and Humphreys [13] proved that the ultimate load carrying capacity of concrete slabs is improved by the addition of fibers at higher fiber volume contents and aspect ratios. Deitz et al. [14] tested unidirectional concrete panels with GFRP alone, a combination of GFRP and steel, and steel only reinforcement. GFRP reinforced panels failed in diagonal tension failure mode under a two-point loading system. Roesler et al. [15] conducted monotonic load tests to examine the effect of fiber type and dosage on the strength properties of concrete slabs. There was a significant increase in 
the flexural strength of fiber reinforced concrete slabs. It also showed that the fibers helped crack propagation resistance and load redistribution. Venkatesh et al. [16] conducted experimental studies to investigate the thermal performance of concrete slabs reinforced with carbon and glass fiber reinforced polymer bars under fire condition. It has been determined that the heat transfer behavior of concrete slabs reinforced with FRP bars is similar to that of slabs reinforced with steel reinforcements. In addition, the thickness of the concrete cover and the type of reinforcement were determined to be the key parameters affecting the fire resistance of FRP reinforced concrete slabs. AlSayed et al. [17] performed four-point bending test on a total of eight full-size slabs with varying parameters such as different FRP bar types and ratios. All test slabs failed shear before the design had reached its bending capacity. Kodur et al. [18] investigated the effect of reinforcement type on the fire performance of reinforced concrete slabs. It shows that concrete slabs reinforced with FRP have lower fire resistance than slabs reinforced with conventional reinforcing steel. Kurtoğlu [19] investigated the punching strength of bidirectional slabs reinforced with GFRP bars. GFRP composites are a linear elastic material. Therefore, the yield point does not observe and the material suddenly ruptures. Another material that exhibits brittle behavior like GFRP is concrete. Many studies have been carried out to improve the brittle behavior of concrete. The problem can be minimized by adding different fibers to fresh concrete. Currently, steel, nylon, and polypropylene fibers are commonly used in the production of this flexible concrete. The fibers increase concrete's bending strength, ductility, and energy consumption capacity against tensile stress, and crack propagation. Fiber improves the properties of concrete [20-22]. When the fiber ratio in the concrete mixture is about $0.5 \%$, some chemical additives must be added for a workability of concrete [23-25]. Dharan and Lal [26] added different percentages $(0.5 \%, 1 \%, 1.5 \%$, $2 \%$ ) of polypropylene fibers to the concrete. Experimental study was conducted to investigate the parameters such as compressive strength, bending capacity, modulus of elasticity, and workability. Gemi and Köroğlu [27] investigated the bending behavior of beams reinforced with polypropylene fiber, steel, and GFRP bars. It has been observed that GFRP bars significantly improve bending performance of beams. Hrynyk et al. [28] investigated the behavior of seven mediumsized slabs under weight-drop impacts. The slabs were constructed with longitudinal rebars and steel fiber contents ranging from zero to $1.50 \%$ by volume. It showed that the addition of steel fibers was effective in increasing slab capacity, reducing crack widths and spacing, and reducing local damage under impact.

In this study, five slabs reinforced with polypropylene fiber, steel and GFRP bars were produced. All slabs were subjected to monotonic increasing distributed loading until collapse. The effect of GFRP bar and polypropylene fiber on the slabs' bending behavior was investigated both experimentally and numerically. Slabs were modeled via ABAQUS. The load-displacement relation and damage situation obtained from the experimental and numerical results were compared. It is observed that the results are compatible with each other.

\section{Material and method}

\subsection{Material tests}

The concrete casting of all specimens has been made together using ready-mixed concrete. The compressive strength of the concrete is approximately $20 \mathrm{MPa}$. Steel and GFRP composite bars are $8 \mathrm{~mm}$ in diameter. Tensile testing of GFRP bars has been carried out according to ASTM D3039 standard [29]. The GFRP bars have been pulled at a speed of $2 \mathrm{~mm} / \mathrm{min}$. The tensile tests of these bars and the damage situations are shown in Fig. 1. As a result of the tests, the stress-strain relation of the GFRP bars is presented in Fig. 2.

As a result of uniaxial tension tests, GFRP bars' tensile strength and elongation are obtained 630 $\mathrm{MPa}$ and 5\%, respectively. The modulus of elasticity and material density values have been obtained from the manufacturer. 


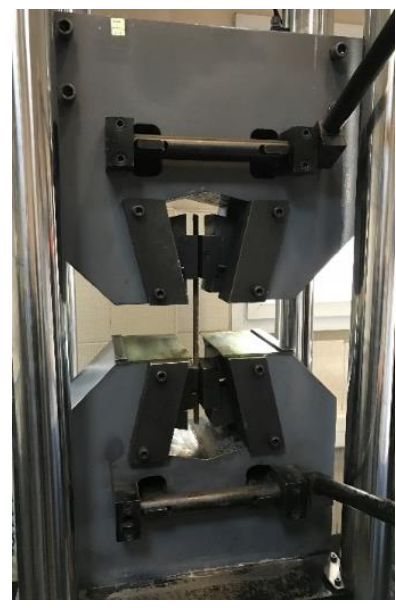

(a)Tensile tests

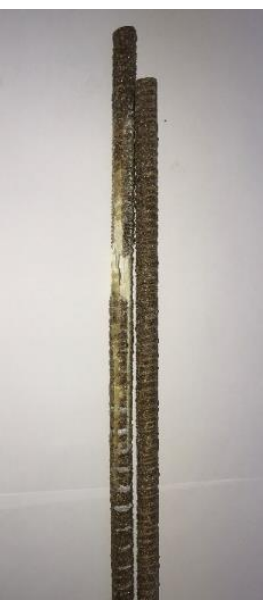

(b) Damage cases

Fig. 1 Tensile tests of GFRP reinforcements and damage cases

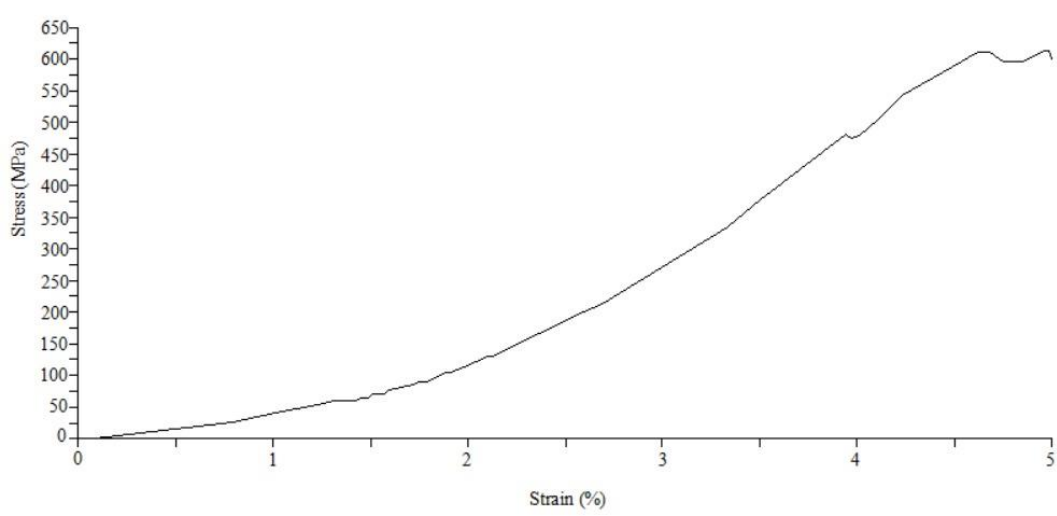

Fig. 2 Stress-strain relation of GFRP bars

For modulus of elasticity and material density, these values are $47000 \mathrm{MPa}$ and $1950 \mathrm{~kg} / \mathrm{m} 3$, respectively. The fiber and resin contents of the GFRP bar are $80 \%$ and $20 \%$, respectively. GFRP bars are exhibited brittle behavior in the tests. The comparison of the properties of GFRP bars according to the ACI 440.1R-15 guide is presented in Table 1 [30]. The material and mechanical properties of the produced GFRP bars have provided the requirements of the ACI 440.1R-15 guide.

\subsection{General properties of slabs}

In this study, five slab specimens were produced. Test specimens are called SS-1, SS-2, GFRPS-1,
GFRPS-2, and GFRPS-F. The general properties of the slab specimens are presented in Table 2.

Due to the fact that GFRP is a brittle material, polypropylene fiber was used to increase the tensile and flexure strength. Thus, it was aimed to limit the formation of cracks and improve the ductility of the GFRP slab. In the studies, it was determined that adding $5 \%$ fiber by volume to concrete gave good results [31].

Therefore, 5\% fiber was preferred in the GFRPS-F slab. Technical properties of the polypropylene fiber used are presented in Table 3. The dimensions of all slabs were $120 \times 200 \times 12 \mathrm{~cm}$. Steel and GFRP bars were placed in all slabs at intervals of $15 \mathrm{~cm}$ in both directions. Slabs were designed according to TS 500-2000 standards [32]. 
Table 1. Comparison of the properties of GFRP bars according to the ACI 440.1R-15 guide

\begin{tabular}{lcc}
\hline \multicolumn{2}{c}{ ACI 440.1R-15 } & GFRP \\
\hline $\begin{array}{l}\text { Density (kg/m3) } \\
\text { Tensile strength (MPa) }\end{array}$ & 483 to 690 & 630 \\
$\begin{array}{l}\text { Modulus of elasticity } \\
\text { (MPa) }\end{array}$ & 35 to 51 & 47 \\
\hline
\end{tabular}

Table 2. Bar properties of slab specimens

\begin{tabular}{lll}
\hline Slab Code & Tension members in the slab & \\
\hline SS-1 & B420C Steel reinforcement & \\
SS-2 & B420C Steel reinforcement & \\
GFRPS-1 & GFRP reinforcement & \\
GFRPS-2 & GFRP reinforcement & \\
GFRPS-F & GFRP reinforcement & Polypropylene fiber \\
&
\end{tabular}

Table 3. Properties of polypropylene fiber

\begin{tabular}{ll}
\hline \multicolumn{2}{c}{ Specifications } \\
\hline Specific weight $\left(\mathrm{kg} / \mathrm{m}^{3}\right)$ & 910 \\
Yarn length $(\mathrm{m})$ & 0.018 \\
Electrical conductivity & Low \\
Acid and salt resistance & High \\
Melting point & $162{ }^{\circ} \mathrm{C}$ \\
İgnition point & $593{ }^{\circ} \mathrm{C}$ \\
Heat conductivity & Low \\
Alkali resistance & Alkali proof \\
Tensile strength (MPa) & $300-400$ \\
Modulus of elasticity (MPa) & 4000 \\
\hline
\end{tabular}

The geometrical properties of the slabs are shown in Fig. 3.

\section{Experimental study}

The slabs were loaded monotonically up to their maximum load carrying capacity to investigate the load-displacement behavior. A hydraulic loading device with a capacity of $250 \mathrm{kN}$ was used for all slabs, and the slabs were subjected to distributed loading from the middle of the span with a $120 \mathrm{~mm}$ length steel apparatus.

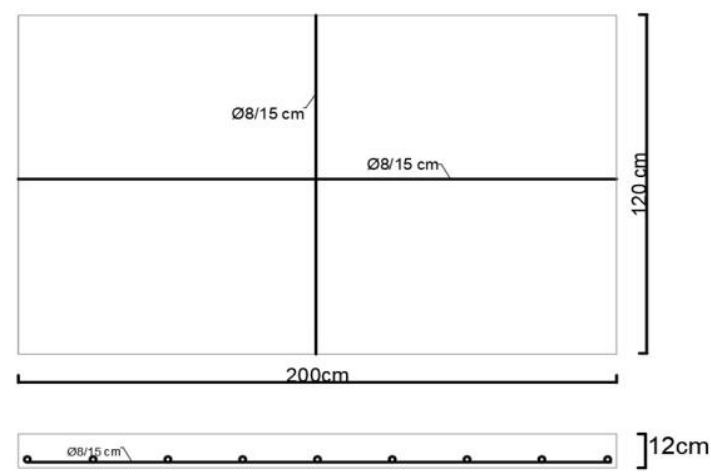

(a) Geometrical properties

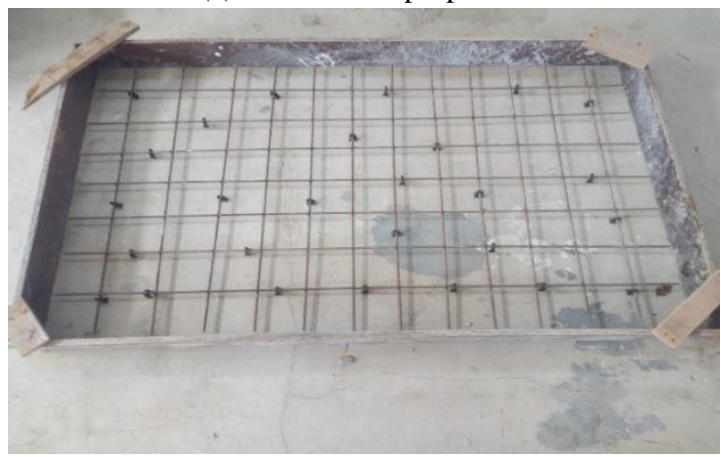

(b) Reinforcement details

Fig. 3 Geometrical properties and reinforcement details of the slabs

Three-point bending tests were performed for all slabs. The distance between the two supports is $1700 \mathrm{~mm}$. It was ensured that one of the supports was movable and the other was a pinned support. Linear variable differential transformer (LVDT) were used for the displacement measurements. One LVDT was placed in the middle span of the slabs. The testing set up is shown in Fig. 4.

\subsection{Experimental results}

All slabs were subjected to monotonic increasing distributed loading. During experiment, load and displacement values transferred to the computer by using the data collection system. The loaddisplacement relations of the slabs and experimental results are shown in Fig. 5 and Table 4 , respectively. 


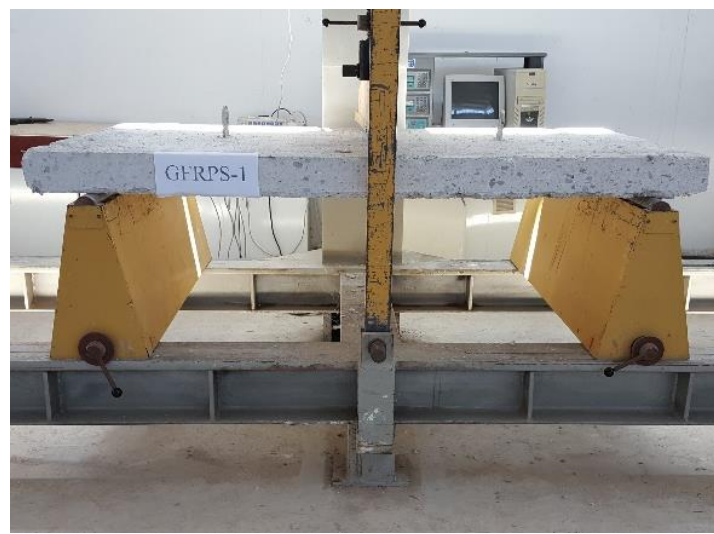

Fig. 4 Testing set up of slabs

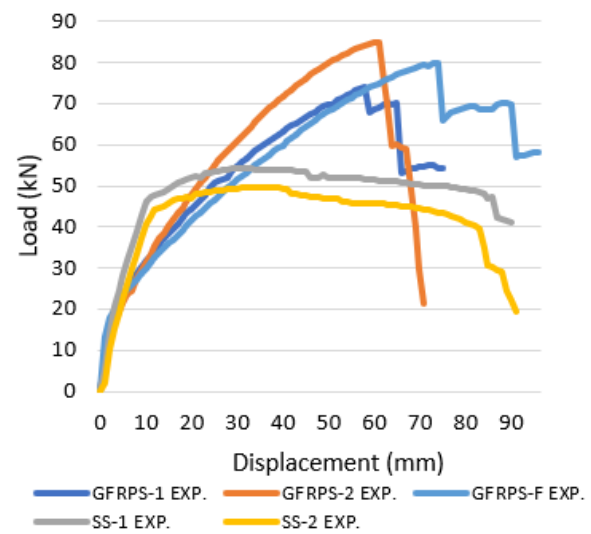

Fig. 5. Load-displacement relations of the slabs

Table 4. Experimental results of the slabs

\begin{tabular}{lcccccc}
\hline Code & $\begin{array}{c}\text { Ultimate } \\
\text { Load } \\
(\mathrm{kN})\end{array}$ & $\begin{array}{c}\text { Average } \\
\text { Load } \\
(\mathrm{kN})\end{array}$ & $\begin{array}{c}\text { Ultimate } \\
\text { Displacement } \\
(\mathrm{m})\end{array}$ & $\begin{array}{c}\text { Average } \\
\text { Displacement } \\
(\mathrm{m})\end{array}$ & $\begin{array}{c}\text { Energy Consumption } \\
\text { Capacity } \\
(\mathrm{kN} . \mathrm{m})\end{array}$ & $\begin{array}{c}\text { Average Energy } \\
\text { Consumption Capacity } \\
(\mathrm{kN} . \mathrm{m})\end{array}$ \\
\hline GFRPS-1 & 75.40 & 80.975 & 0.058 & 0.0605 & 4.03295 & 4.07471 \\
GFRPS-2 & 86.55 & & 0.061 & & 4.11647 & 5.60647 \\
GFRPS-F & 81.50 & 81.50 & 0.074 & 0.074 & 5.60647 & 4.17146 \\
SS-1 & 55.50 & & 0.086 & & 4.43293 & \\
SS-2 & 50.65 & 53.075 & 0.083 & 0.0845 & 3.91000 & \\
\hline
\end{tabular}

The first cracks in the SS-1 and SS-2 slabs occurred at load levels of 25.6 and $22.6 \mathrm{kN}$, respectively. These cracks in the GFRPS slabs were formed at load levels of 24.65 and $21.1 \mathrm{kN}$, respectively. Crack formation in GFRP slabs occurred at a lower load compared to SS slabs. It was observed that the cracks in the GFRP slabs are much and larger than those of the SS slabs. The first crack in GFRPS-F slab was observed at load levels of $21.98 \mathrm{kN}$. The number of cracks in the GFRPSF slab decreased compared to the GFRPS slab. According to experimental results, GFRPS-2, GFRPS-F, GFRPS-1, SS-1, and SS-2 carried the highest load, respectively. The average ultimate load of GFRPS-F slab is $0.64 \%$ and $53.6 \%$ higher than GFRPS and SS slabs, respectively. When the specimens were compared according to the ultimate displacement values, the largest displacements were observed in the SS-1, SS-2, GFP-F, GFP-2 and GFRP-1 slabs, respectively. Average displacement value of the SS slab is $39.7 \%$ and $15 \%$ larger than GFRPS and GFRPS-F slabs, respectively. By using GFRP bar and polypropylene fiber together, higher displacement and energy consumption capacities were obtained. According to average energy consumption capacity, the GFRPS-F slab consumed $34.4 \%$ and $37.6 \%$ more energy than SS and GFRPS slabs, respectively. When the SS slabs failured, a single crack was observed under the slab in the maximum moment region, while numerous cracks were observed in this region and around in other slabs. The theoretical load carrying capacities of SS and GFRPS slabs have been calculated according to TS 500-2000 standard and ACI 440.1R-15 guide. The theoretical load carrying capacities of SS and GFRPS slabs are 35.25 and $51.93 \mathrm{kN}$, respectively. Damages in the failured slabs are shown in Figs. 6 and 7. 

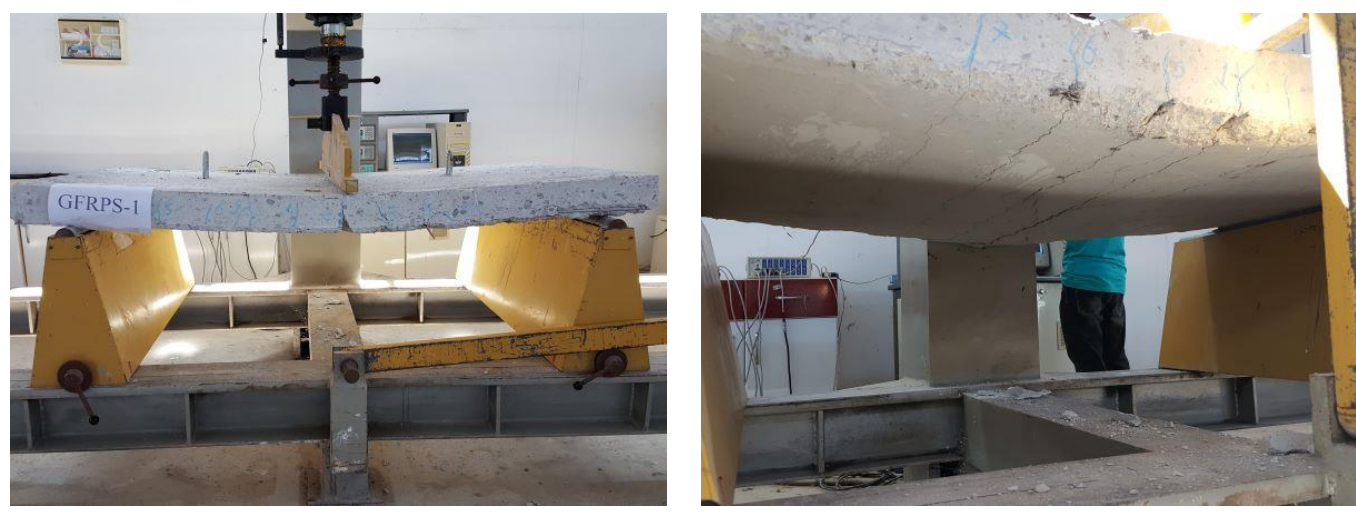

(a)
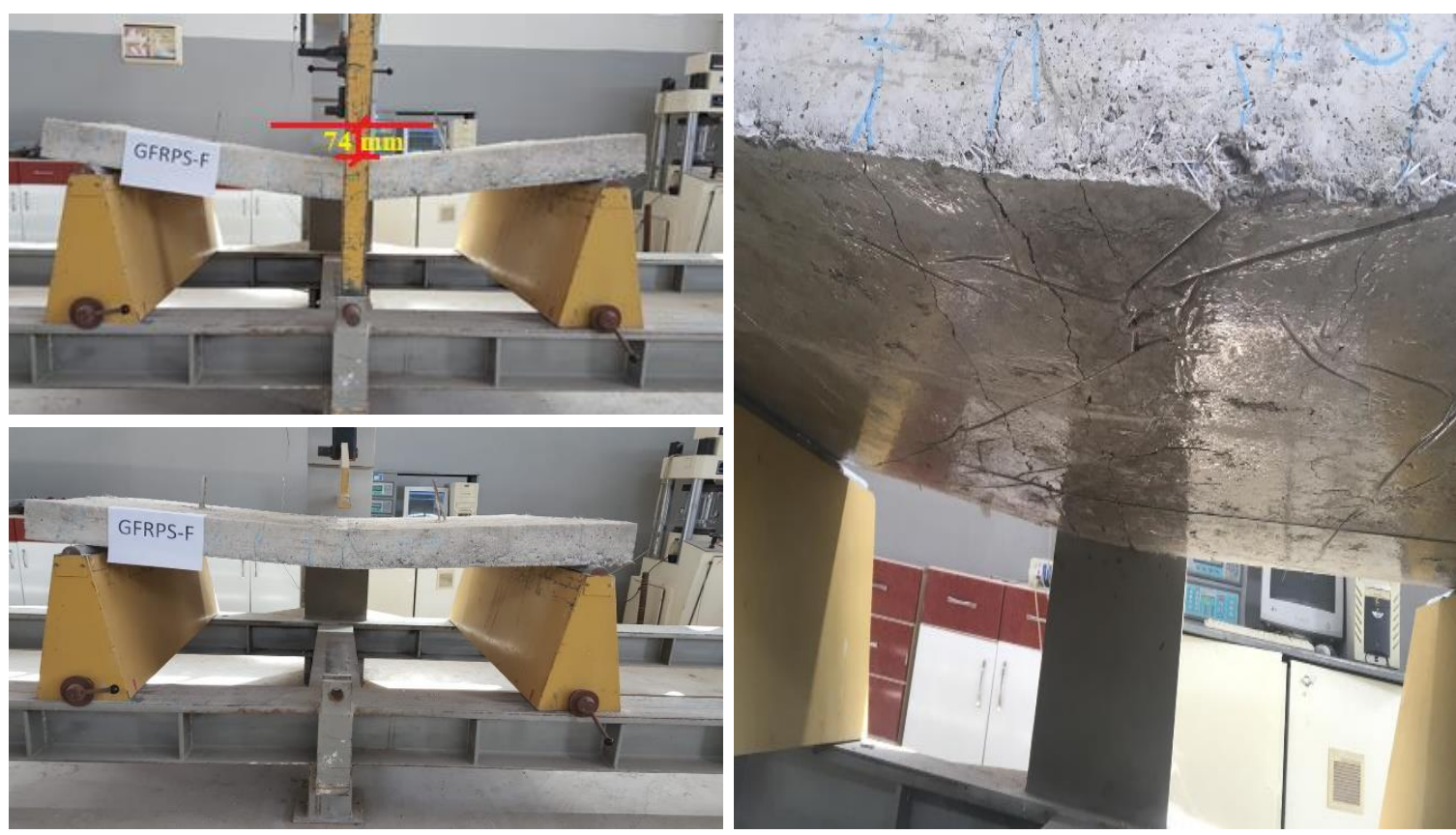

(b)

Fig. 6. Damage situations of GFRPS and GFRPS-F slabs after loading
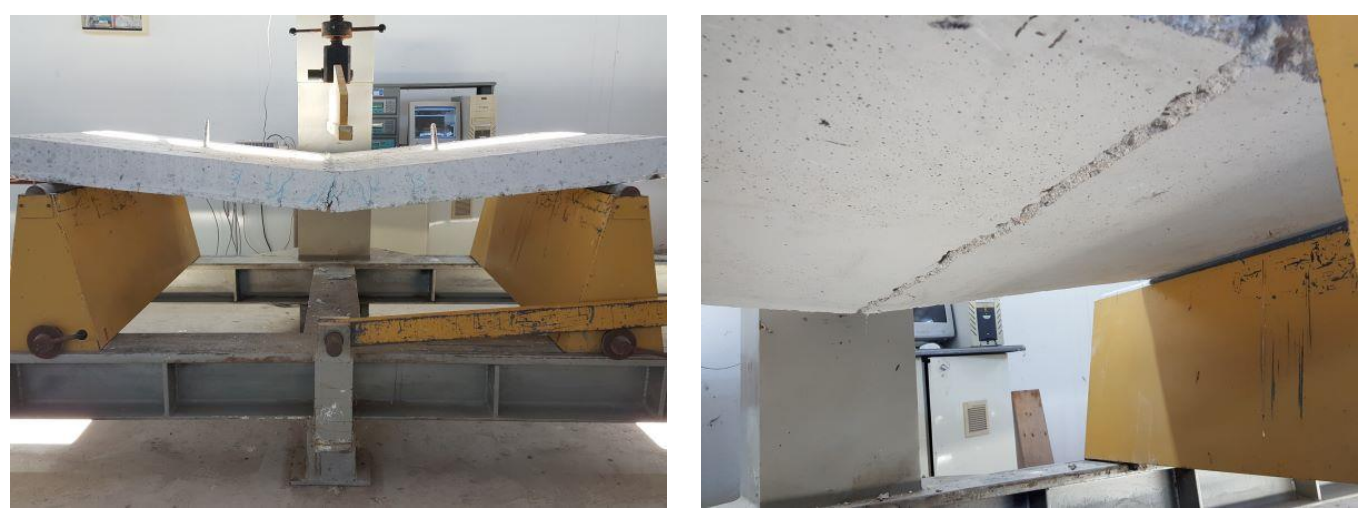

Fig. 7. Damages of SS slabs after loading 


\section{Finite element modeling}

Numerical analyses of GFRPS and SS slabs were performed by using ABAQUS software [33]. The material properties defined for the slabs are presented in Table 5 [34].

Concrete was modeled as solid element (C3D8R). 1400 elements were used in the concrete model. GFRP and steel bars were modeled by using the beam element (B31). The number of elements of both bar was 39. 24262 nodes and 12869 quadratic tetrahedral elements of type C3D10 were used in all models. It was assumed that steel bars exhibit elasto-plastic behavior. The behavior of GFRP bars was linear elastic up to rupture strain. This material model was used for GFRP bars. Boundary conditions were defined for the supports. The load was applied as a vertical displacement. The numerical analyses were carried out with displacement controlled.

The Concrete Damage Plasticity (CDP) material model was used to describe the nonlinear material behavior of concrete. The parameters of the CDP material model are given in Table 6 .

The time was chosen as 10 seconds to avoid the impact of the force. The maximum principal stresses and displacements are presented in Fig. 8.

It is seen that the load-displacement relations obtained from the tests and numerical analyses of

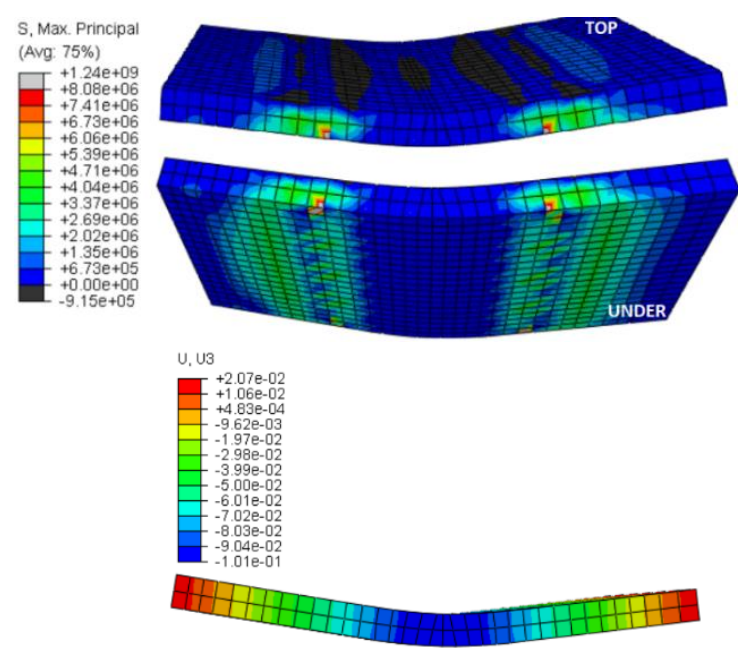

a) Principal stresses and displacements of GFRPS
SS and GFRPS slabs are quite compatible. As shown in Figs. 9a and 9b, the ultimate load of the SS and GFRPS slab are 52.342 and $79.765 \mathrm{kN}$, respectively. These values are very close to the average ultimate load test values. The difference between the values is about $1.5 \%$. Numerical model realistically reflects test specimens.

\section{Discussions}

The comparison of the numerical and experimental results of the SS and GFRPS slabs is presented in Fig. 10. According to experimental results, the average ultimate loads of SS and GFRPS slabs are 53.075 and $80.975 \mathrm{kN}$, respectively.

Table 5. Properties of material

\begin{tabular}{lccc}
\hline Properties of Material & GFRP & Steel & Concrete \\
\hline $\begin{array}{l}\text { Density }\left(\mathrm{kg} / \mathrm{m}^{3}\right) \\
\begin{array}{l}\text { Modulus of elasticity } \\
\text { (GPa) }\end{array}\end{array}$ & 1950 & 7850 & 2400 \\
Poisson's ratio & 0.28 & 0.3 & 0.2 \\
\hline
\end{tabular}

Table 6. CDP material parameters

\begin{tabular}{ccccc}
\hline $\begin{array}{c}\text { Angle of } \\
\text { dilation }\end{array}$ & Eccentricity & $\mathrm{fb} 0 / \mathrm{fc} 0$ & $\mathrm{~K}$ & $\begin{array}{c}\text { Viscosity } \\
\text { parameter }\end{array}$ \\
\hline $32^{0}$ & 0.1 & 1.16 & 0.67 & 0.01 \\
\hline
\end{tabular}
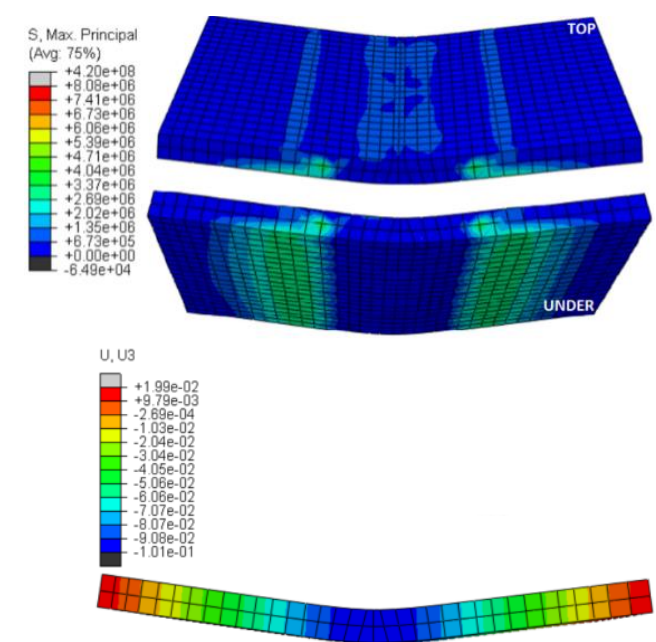

b) Principal stresses and displacements of SS

Fig. 8. Principal stresses and displacements obtained from numerical analyses 


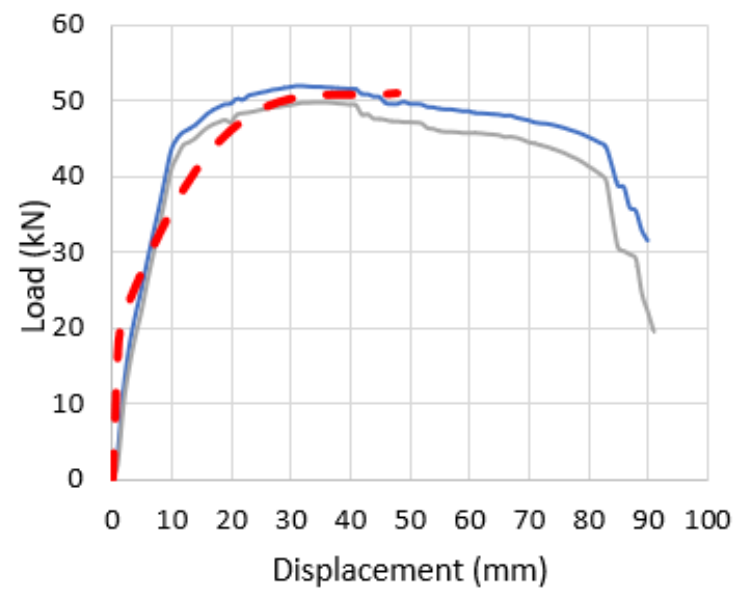

SS-1 EXP.

SS-2 EXP. - - SS FEM

a) Load-displacement graphs of SS

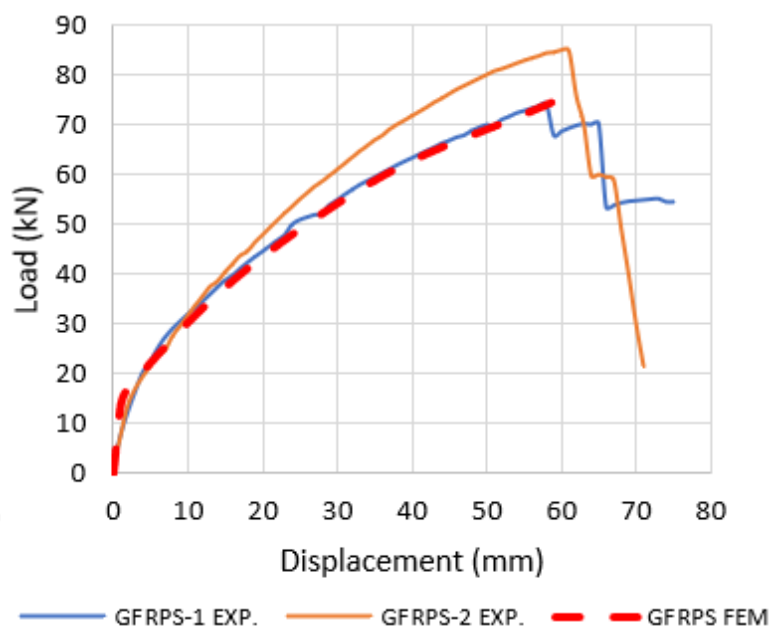

b) Load-displacement graphs of GFRPS

Fig. 9 Experimental and numerical load-displacement graphs of SS and GFPS slabs

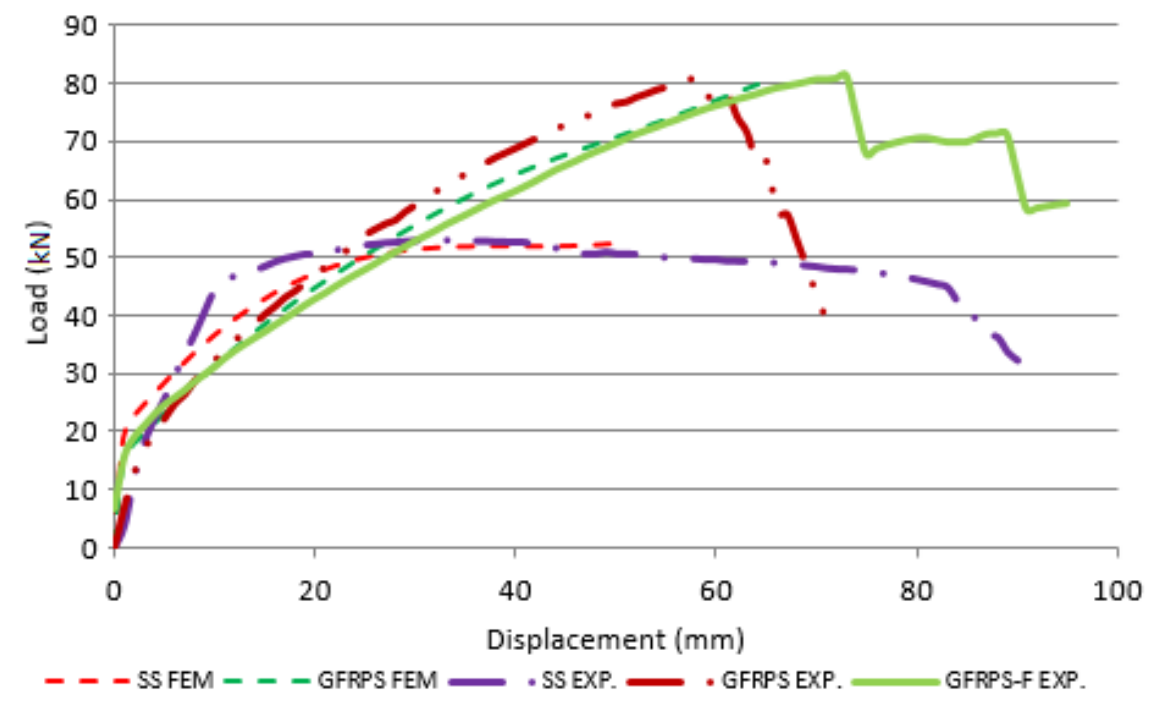

Fig. 10 Comparison of experimental and numerical results

The GFRPS slab carried 53\% higher load than that of SS slab. Experimental and numerical results are quite compatible with each other. This result shows that the developed FE model is quite realistic. The experimental average ultimate loads of the SS and GFRPS slabs are 50.56\% and 55.93\% higher than the theoretical load, respectively. According to the theoretical calculate, the carrying capacity of the GFRPS slab is $47 \%$ more than the SS slabs.

After loading, a large crack was observed throughout steel bars in the center of the SS slabs.
However, many cracks occurred in the GFRPS slabs and they were parallel to the GFRP bars. GFRP slabs returned closer to their initial position after the loading was removed. In the SS slabs, it was observed that the damage was more permanent and could not return to its former position. Due to the polypropylene fiber added to the concrete in the GFRPS-F slab, the cracks decreased and approached the center. It was also observed that GFRPS-F exhibited elastoplastic behavior and more returned to its initial position compare to others. When the energy consumption capacities are 
investigated, the average energy consumption capacities of SS slabs are $2.4 \%$ higher than GFRPS slabs. According to these results, it is seen that the energy consumption capacities of slabs with steel and glass are quite close. In addition, it was determined that the energy consumption increased with the addition of polypropylene fibers.

\section{Conclusions}

In this study, the bending behavior of slabs with different tensile reinforcement was investigated both experimental and numerical. Loaddisplacement relations were obtained for each slab. The energy consumption capacities of the slabs were calculated using load-displacement curves obtained from the experimental results. In addition, ultimate load, ultimate displacement, and energy consumption capacity of a slab with polypropylene fibers added to fresh concrete were obtained and compared with other slabs.

Although GFRPS slabs reached the highest load, SS slabs reached the highest displacement, and the GFRPS-F slab consumed the maximum energy. Experimental load carrying capacities of slabs are approximately 1.5 times the calculated theoretical loads. The average and theoretical load carrying capacities of GFRPS slabs are 1.53 and 1.47 times that of SS slabs, respectively. It was seen that the average load carrying capacities of GFRPS and GFRP-F slabs were approximately equal. The use of fiber in the GFRP-F slab improved the bending behavior. The average displacement of the GFRP-F slab increased by $22.3 \%$ compared to the GFRPS slab. However, the average displacement of the SS slab is $15 \%$ greater than GFRPS-F slab. The average energy consumption capacities of SS and GFRPS slabs are quite close to each other. The average energy consumption capacity of the GFRPS-F was obtained by $37.6 \%$ and $34.4 \%$ more than GFRPS and SS slab, respectively. Initially, all slabs exhibited linear load-displacement behavior. A significant stiffness reduction was observed in the GFRPS slabs, after the initial cracks formed in the test specimens. Due to the low modulus of elasticity of the GFRP material, the displacement values and the number of cracks increased rapidly.
GFRPS slabs had much more cracks than SS slabs. According to the GFRPS slab, the crack widths decreased in the GFRPS-F. Thus, crack control was improved. GFRPS-F slab exhibited almost elastoplastic behavior. After loading, it returned the nearly initial position. Experimental and numerical load-displacement curves were obtained to be compatible.

According to these results, polypropylene fibers have significantly contributed to the tensile behavior of concrete, and the GFPRS-F slab has exhibited better ductility and more energy consumption than all slabs. Finally, it is concluded that GFRP composite bars can be safely used in field concretes, concrete roads, prefabricated panel walls, and slabs.

\section{Declaration of conflicting interests}

The author(s) declared no potential conflicts of interest with respect to the research, authorship, and/or publication of this article.

\section{References}

[1] Doğan M (2009) Betonarme yapılardaki deprem hasarlarına korozyonun etkisi. Eskişehir Osman Gazi Üniversitesi Mühendislik ve Mimarlık Fakültesi Dergisi 22:147-168 (in Turkish).

[2] Barris C, Torres L, Turon A, et al (2009) An experimental study of the flexural behavior of GFRP RC beams and comparison with prediction models. Compos Struct 91:286-295.

[3] Qin R, Zhou A, Lau D (2017) Effect of reinforcement ratio on the flexural performance of hybrid FRP reinforced concrete beams. Compos Part B Eng 108:200-209.

[4] Wang YC, Wong PMH, Kodur V (2007) An experimental study of the mechanical properties of fibre reinforced polymer (FRP) and steel reinforcing bars at elevated temperatures. Compos Struct 80:131-140.

[5] Krasniqi C, Kabashi N, Krasniqi E, Kaqi V (2018) Comparison of the behavior of GFRP reinforced concrete beams with conventional steel bars. Pollack Period 13:141-150.

[6] Tu J, Gao K, He L, Li X (2019) Experimental study on the axial compression performance of GFRPreinforced concrete square columns. Adv Struct Eng 22:1554-1565. 
[7] Şahin A (2019) Effects of Reinforcement Arrangement on Flexural Behavior in GFRP and Steel Reinforced Hybrid Beams. MSc Thesis, Kırıkkale University.

[8] Unsal I, Tokgoz S, Cagatay IH, Dundar C (2017) A study on load-deflection behavior of two-span continuous concrete beams reinforced with GFRP and steel bars. Struct Eng Mech 63:629-637.

[9] Maranan GB, Manalo AC, Benmokrane B, et al (2019) Flexural behavior of geopolymer-concrete beams longitudinally reinforced with GFRP and steel hybrid reinforcements. Eng Struct 182:141152.

[10] Abdalla HA (2002) Evaluation of deflection in concrete members reinforced with fiber reinforced polymer (FRP) bars. Compos Struct 56:63-71.

[11] Elamary AS, Abd-Elwahab RK (2016) Numerical simulation of concrete beams reinforced with composite GFRP-Steel bars under three points bending. Struct Eng Mech 57:937-949.

[12] Sham SHR, Burgoyne CJ (1986) Load tests on dramix steel fibre reinforced concrete slabs. Rep Sir Frederick Snow Partn Consult Eng Imp Coll Sci Technol Dep Civ Eng Concr Lab.

[13] Beckett D (1990) Comparative tests on plain, fabric reinforced and steel fibre reinforced concrete ground slabs. Concr Lond 24:43-45.

[14] Deitz DH, Harik IE, Gesund H (1999) One-way slabs reinforced with glass fiber reinforced polymer reinforcing bars. Spec Publ 188:279-286.

[15] Roesler JR, Lange DA, Altoubat SA, et al (2004) Fracture of plain and fiber-reinforced concrete slabs under monotonic loading. J Mater Civ Eng 16:452-460.

[16] Kodur VK, Bisby LA, Foo SH (2005) Thermal behavior of fire-exposed concrete slabs reinforced with fiber-reinforced polymer bars. ACI Struct J 102:799.

[17] El-Sayed A, El-Salakawy E, Benmokrane B (2005) Shear strength of one-way concrete slabs reinforced with fiber-reinforced polymer composite bars. J Compos Constr 9:147-157.

[18] Kodur VKR, Bisby LA (2005) Evaluation of fire endurance of concrete slabs reinforced with fiberreinforced polymer bars. J Struct Eng 131:34-43.

[19] Kurtoğlu AE (2016) Punching Shear Capacity of Two-Way Slabs Reinforced with Glass Fiber Reinforced Polymer (GFRP) Rebars. PhD Thesis, Gaziantep University.
[20] Saatci S, Batarlar B (2017) Behavior of steel fiber reinforced concrete beams without stirrups. Gazi Univ J Fac Eng Archit 32:1143-1154.

[21] Bozkurt H, Karakurt C (2010) Road pavement characteristics on steel fiber mixed concrete. Duzce University Journal of Science \& Technology 4:617-624.

[22] Aryan A (2014) Experimental and Analytical Study of Polypropylene Fiber Reinforced Concrete Beams. MSc Thesis, Selçuk University, Graduate School of Natural and Applied Sciences.

[23] Köroğlu MA, Özdöner N (2016) Behavioral study of steel fiber and polypropylene fiber reinforced concrete. In: Key Engineering Materials. Trans Tech Publ, pp 59-63.

[24] Kakooei S, Akil HM, Jamshidi M, Rouhi J (2012) The effects of polypropylene fibers on the properties of reinforced concrete structures. Constr Build Mater 27:73-77.

[25] Demir A (2015) Prediction of hybrid fiber-added concrete strength using artificial neural networks. Comput Concr 15:503-514.

[26] Dharan DS, Lal A (2016) Study the effect of polypropylene fiber in concrete. Int Res J Eng Technol 3:616-619.

[27] Gemi L, Köroğlu A (2018) Bending behavior and failure analysis of GFRP and steel rebar reinforced beam without transverse reinforcement with fiber reinforced concrete in tension zone. Selcuk University Journal of Engineering, Science \& Technology, 6(4), 654-667.

[28] Hrynyk TD, Vecchio FJ (2014) Behavior of steel fiber-reinforced concrete slabs under impact load. Struct J 111:1213-1224.

[29] ACI 440.1R-15. Guide for the Design and Construction of Structural Concrete Reinforced with Fiber-Reinforced Polymer (FRP) Bars.

[30] Higgins IC (2020) Impact of Changes in the Design Methodology between the American Concrete Institute's Draft Code Provisions for GFRPReinforced Concrete and the ACI 440.1 R-15 Guide for the Design and Construction of Structural Concrete Reinforced with FRP Bars. PhD Thesis, Widener University

[31] Blazy J, Blazy R (2021) Polypropylene fiber reinforced concrete and its application in creating architectural forms of public spaces. Case Studies in Construction Materials 14:1-19.

[32] TS 500. Requirements for Design and Construction of Reinforced Concrete Structures. 
[33] ABAQUS. (2012) Simulia Inc. Version 6.12. Providence, Rhode Island, USA (Accessed 14 Aug 2021).
[34] Ding Y, Ning X, Zhang Y, et al (2014) Fibers for enhancing of the bond capacity between GFRP rebar and concrete. Constr Build Mater 51:303312. 